\title{
STUDIES ON PROPAGATION METHODS OF KONTHALAUN (Xylocarpus rumphi)
}

\author{
I R Palihakkara, DT L K Deerasinghe, G A Dayatilaka and D L C Kumari \\ Faculty of Agriculture, University of Ruhuna
}

Konthalaun is a rare plant with medicinal and industrial value. Seeds are used for the preparation of Ayurvedic medicine caddied "Gopaluguliya" used as a treatment for food poisoning and snakebites. Since there is only a small population of Konthalaun trees distributed along the coastal belt of Sri Lanka, multiplication and conservation of this plant is of paramount importance.

Using nineteen mother trees of Konthalaun selected from four sites in the Galled district.

This study was conducted at Faculty of Agriculture, University of Ruhuna and in Unawatuna area in Galle district to develop an efficient propagation method. Three propagation methods manly stem cuttings, air layering and full mature viable seeds were used in this study.

Seed germination was observed with five treatments.

$\mathrm{Tl}$ - Soaking in ordinary water (Room $\mathrm{T}^{\mathrm{O}}$ ) for 12 hours

$\mathrm{T} 2$ - Soaking in hot water for 5 minutes (at $55^{\circ} \mathrm{C}$ )

T3 - Peeling the seed coat without damaging the (cotyledents)

T4 - Soaking in $15 \% \mathrm{H}_{2} \mathrm{SO}_{4}$ solution for 2 minute and then wash out with distilled water

T5 - Soaking in sea water for 12 hours

For the stem cuttings three types of cuttings were taken and treated with commercially available homone, (secto) and a control was used (no homones)

T1 - Soft and stem cuttings ( 3 leaves)

$\mathrm{T} 2$ - Sproutings ( 3 leaves)

T3 - Hard wood stem cuttings ( 3 leaves)

Hard wood and soft wood branches were air layered. These branches were treated with secto and those without secto also severed as the control

Sea water treated seeds showed the highest percentage of germination while the lowest germination percentage was observed in peeled seeds.

Three weeks later all the cuttings showed sprouting. But six weeks later all sprouted cuttings in all treatments withered and died.

After four months all treatments including the control showed root primodia initiation but the number of root primodia was higher in soft wood than hard wood cultings. Results showed that seed propagation (seed soaked in sea water) is the easiast method but air layering could also be used as an alternative method.

Proceedings of the Ninth Annual Forestry and Environment Symposium 2003 of the Department of Forestry and Environmental Science, University of Sri Jayewandenepura, Sri Lanka 